\title{
Composite Scoring System and Optimal Tumor Budding Cut-Off Number for Estimating Lymph Node Metastasis in Submucosal Colorectal Cancer
}

Jeong-ki Kim

Chung-Ang University Hospital

\section{Ye-Young Rhee}

Seegene Medical Foundation

Jeong Mo Bae

Seoul National University College of Medicine

Jung Ho Kim

Seoul National University College of Medicine

Seong-Joon Koh

Seoul National University College of Medicine

Hyun Jung Lee

Seoul National University College of Medicine

Jong Pil Im

Seoul National University College of Medicine

Min Jung Kim

Seoul National University College of Medicine

\section{Seung-Bum Ryoo}

Seoul National University College of Medicine

\section{Seung-Yong Jeong}

Seoul National University College of Medicine Kyu Joo Park

Seoul National University College of Medicine Ji Won Park ( $\square$ sowisdom@gmail.com )

Seoul National University College of Medicine Gyeong Hoon Kang

Seoul National University College of Medicine

\section{Research Article}

Keywords: Colorectal neoplasm, Histopathology, Lymph nodes metastasis, Tumor budding 
Posted Date: December 29th, 2021

DOI: https://doi.org/10.21203/rs.3.rs-1132994/v1

License: (c) (i) This work is licensed under a Creative Commons Attribution 4.0 International License. Read Full License 


\section{Abstract \\ Background}

Tumor budding is associated with lymph node (LN) metastasis in submucosal colorectal cancer (CRC). However, the rate of LN metastasis associated with the number of tumor buds is unknown. Here, we determined the optimal tumor budding cut-off number and developed a composite scoring system (CSS) for estimating LN metastasis of submucosal CRC.

\section{Methods}

In total, 395 patients with histologically confirmed T1N0-2M0 CRC were evaluated. The clinicopathological characteristics were subjected to univariate and multivariate analyses. The Akaike information criterion (AIC) values of the multivariate models were evaluated to identify the optimal cut-off number. A CSS for LN metastasis was developed using independent risk factors.

\section{Results}

The prevalence of LN metastasis was 13.2\%. Histological differentiation, lymphatic or venous invasion, and tumor budding were associated with LN metastasis in univariate analyses. In multivariate models adjusted for histological differentiation and lymphatic or venous invasion, the AIC value was lowest for five tumor buds. Unfavorable differentiation (odds ratio [OR], 8.16; 95\% confidence interval [CI], 1.8036.89), lymphatic or venous invasion (OR, $5.91 ; 95 \% \mathrm{Cl}, 2.91-11.97)$, and five or more tumor buds (OR, $3.01 ; 95 \% \mathrm{Cl}, 1.21-7.69)$ were independent risk factors. In a CSS using these three risk factors, the rates of LN metastasis were $5.6 \%, 15.5 \%, 31.0 \%$, and $52.4 \%$ for total composite scores of $0,1,2$, and $\geq 3$, respectively.

\section{Conclusions}

For the estimation of LN metastasis in submucosal CRC, the optimal tumor budding cut-off number was five. Our CSS can be utilized to estimate LN metastasis.

\section{Introduction}

Colorectal cancer (CRC) is a major cause of cancer-associated mortality and is the most common cancer worldwide (1). CRC can be cured by surgical treatment if detected early (stage I) without additional chemotherapy (2). Early CRC is increasingly detected by CRC screening. In early CRC cases, malignant polyps without deep invasion can be treated via endoscopic resection. Further radical surgery may be needed according to the probability of lymph node (LN) metastasis. The identification of risk factors for LN metastasis can assist in formulating a treatment strategy. 
The prevalence of LN metastasis in submucosal CRC is $0-17.3 \%$ (3). The risk factors for LN metastasis in submucosal CRC include histopathological features, such as lymphatic or venous invasion (4-7), poorly differentiated carcinoma $(8,9)$, deep submucosal invasion $(9,10,11)$, and tumor budding $(4-6$, 12). In addition, tumor volume, morphological features, mode of growth, absence of background adenoma, and/or lymphoid infiltration are histopathological factors associated with LN metastasis (8, 9, $13,14)$. Tumor budding is defined as isolated single cells or clusters of up to four cells at the invasive margin (15). Tumor budding is an adverse factor in CRC (16-20). Furthermore, tumor budding is a predictive parameter for $\mathrm{LN}$ metastasis according to the guidelines of the European Society for Medical Oncology (21) and the Japanese Society for Cancer of the Colon and Rectum (22). To our knowledge, few studies have evaluated the optimal point of tumor budding for estimating LN metastasis in submucosal $\mathrm{CRC}$. Here, we determined the optimal tumor budding cut-off number and developed a scoring system to estimate LN metastasis of submucosal CRC.

\section{Materials And Methods}

\section{Study design and ethics}

This was retrospective study determined the optimal tumor budding cut-off number and developed a scoring system to estimate LN metastasis of submucosal CRC. This study was reviewed and approved by the Institutional Review Board of the Seoul National University Hospital Biomedical Research Institute (approval number: H-2107-045-1232). All patients provided written informed consent and approval were obtained from all patients. All procedures were carried out in accordance with the relevant guidelines and regulations.

\section{Patients}

In total, 12,749 patients underwent surgery for CRC at Seoul National University Hospital from January 1, 2002 , to December 31, 2019. Among them, patients who underwent a radical operation for submucosal CRC and had available histopathological reports were eligible for this study. Submucosal CRC was defined as an adenocarcinoma that invaded the submucosal layer and conformed to the classification guidelines of the American Joint Committee on Cancer Staging. Patients who received neoadjuvant therapy or underwent local resection were excluded. Finally, 395 patients were enrolled.

\section{Data collection and pathological review}

Data concerning patients' clinicopathological parameters were collected from the electronic medical records. Sex, age, body mass index, American Society of Anesthesiologists score, carcinoembryonic antigen level, and tumor location were analyzed as clinical characteristics. Right colon cancer was defined as tumors in the cecum, ascending colon, and transverse colon; left colon cancer was defined as cancers in the descending and sigmoid colon; and rectal cancer was defined as tumors in the rectosigmoid junction and the rectum (23). 
Pathological features assessed were tumor histological type, lymphatic or venous invasion, perineural invasion, number of tumor buds, distance from the proximal to the distal margin, number of harvested LNs, and number of metastasized LNs. Tumors were histologically classified as favorable differentiation (well or moderately differentiated carcinoma) or unfavorable differentiation (poorly differentiated, undifferentiated, signet ring cell, or mucinous carcinoma), in accordance with the World Health Organization guidelines. Lymphatic or venous invasion was considered present when tumor cells invaded non-muscle-walled small vessels or large vessels with a smooth muscle layer and/or an elastic lamina layer (Fig. 1) (24). Perineural invasion was considered present when tumor cells reached the peripheral nerve sheath layers. To objectively evaluate tumor budding, we confirmed the existence of isolated single cells or clusters of up to four cells via hematoxylin and eosin staining of tumor tissues; the number of tumor budding in a microscopic field was verified at ·200 magnification (Fig. 2). Pathological slides were assessed by three experienced gastrointestinal pathologists. The assessment of tumor budding was performed by another pathologist.

\section{Statistical analysis}

The clinical characteristics and pathological features were compared according to LN metastasis status to identify risk factors for $L N$ metastasis. Pearson's $\chi^{2}$ test or Fisher's exact test was used to compare categorical variables; Student's $t$-test was used to compare continuous variables. Multivariate logistic regression analysis was performed to identify independent risk factors that were predictive of LN metastasis. To identify the optimal tumor budding cut-off number, the sum of sensitivity and specificity for LN metastasis was established. The cut-off number was determined using the Akaike information criterion (AIC) from the adjusted multivariate models. The tumor budding cut-off values, from 0 to 12 at intervals of 1 , were assessed as an indicator of LN metastasis based on the AIC. The best model exhibited the lowest AIC value. A composite scoring system (CSS) was developed to estimate LN metastasis by adding rounded values of the coefficients of independent risk factors. All statistical analyses were performed using SPSS 22 software (IBM Corp., Armonk, NY, USA). A p-value $<0.05$ was considered statistically significant.

\section{Results}

The prevalence of LN metastasis was $13.2 \%$ (52/395). No clinical characteristics significantly differed between patients with and without LN metastasis (Table 1). Correlations between LN metastasis and pathological features are shown in Table 1. Tumors with LN metastasis had a higher prevalence of unfavorable differentiation $(p=0.022)$ and lymphatic or venous invasion $(p<0.001)$. The number of buds was higher in tumors with LN metastasis than in tumors without LN metastasis $(p=0.001)$. 
Table 1

Univariate analysis of Lymph node (LN) metastasis.

\begin{tabular}{|c|c|c|c|c|}
\hline Parameter & & $\operatorname{LN}(-), n=343$ & $\operatorname{LN}(+), n=52$ & $P$ \\
\hline Age $(y)^{a}$ & Mean & $62.3 \pm 11.0$ & $63.2 \pm 10.5$ & 0.581 \\
\hline \multirow[t]{2}{*}{ Sex } & Male & $225(65.6 \%)$ & $30(57.7 \%)$ & 0.340 \\
\hline & Female & $118(34.4 \%)$ & $22(42.3 \%)$ & \\
\hline $\mathrm{BMI}{ }^{\mathrm{a}}$ & Mean & $23.9 \pm 2.9$ & $23.7 \pm 2.95$ & 0.628 \\
\hline \multirow[t]{4}{*}{ ASA grade* } & 1 & $107(31.2 \%)$ & $15(28.8 \%)$ & 0.957 \\
\hline & II & $218(63.6 \%)$ & $34(65.5 \%)$ & \\
\hline & III & $14(4.1 \%)$ & $2(3.8 \%)$ & \\
\hline & unknown & $4(1.1 \%)$ & $1(1.9 \%)$ & \\
\hline $\mathrm{CEA}^{\mathrm{a}}$ & Mean & $1.9 \pm 2.5$ & $2.1 \pm 2.4$ & 0.637 \\
\hline \multirow[t]{4}{*}{ Location } & Right colon & $80(23.3 \%)$ & $10(19.2 \%)$ & 0.320 \\
\hline & Left colon & $153(44.6 \%)$ & $21(40.4 \%)$ & \\
\hline & Rectum & $109(31.8 \%)$ & $20(38.5 \%)$ & \\
\hline & unknown & $1(0.3 \%)$ & $1(1.9 \%)$ & \\
\hline \multirow[t]{2}{*}{ Histologic type } & Favorable & $321(98.5 \%)$ & $46(92.0 \%)$ & 0.022 \\
\hline & Unfavorable & $5(1.5 \%)$ & $4(8.0 \%)$ & \\
\hline \multirow[t]{3}{*}{ Lymphatic or venous invasion } & Negative & $304(88.6 \%)$ & $28(53.8 \%)$ & $<0.001$ \\
\hline & Positive & $36(10.5 \%)$ & $21(40.4 \%)$ & \\
\hline & unknown & $3(0.9 \%)$ & $3(5.8 \%)$ & \\
\hline \multirow[t]{3}{*}{ Perineural invasion } & Negative & 324 (94.5\%) & $48(92.3 \%)$ & 1.000 \\
\hline & Positive & $2(0.5 \%)$ & $0(0 \%)$ & \\
\hline & unknown & $17(5.0 \%)$ & $4(7.7 \%)$ & \\
\hline Tumor budding $(n)^{a}$ & & $2.2 \pm 3.6$ & $4.0 \pm 4.1$ & 0.001 \\
\hline Tumor size $(\mathrm{cm})^{\mathrm{a}}$ & & $1.97 \pm 2.50$ & $2.35 \pm 2.82$ & 0.058 \\
\hline
\end{tabular}

Abbreviations: BMI, body mass index; ASA, American Society of Anesthesiologist; CEA, carcinoembryonic antigen

a. Mean \pm standard error of the mean (SEM) 


\begin{tabular}{|lccc|}
\hline Parameter & LN (-), $\mathbf{n = 3 4 3}$ & LN (+), $\mathbf{n = 5 2}$ & $P$ \\
\hline Harvest LNs $(\mathrm{n})^{\mathrm{a}}$ & $18.2 \pm 14.3$ & $18.2 \pm 9.4$ & 0.980 \\
\hline Proximal margin $(\mathrm{cm})^{\mathrm{a}}$ & $13.9 \pm 13.8$ & $13.3 \pm 12.8$ & 0.769 \\
\hline Distal margin (cm) & $6.9 \pm 9.8$ & $8.5 \pm 9.9$ & 0.297 \\
\hline $\begin{array}{l}\text { Abbreviations: BMl, body mass index; ASA, American Society of Anesthesiologist; CEA, } \\
\text { carcinoembryonic antigen }\end{array}$ & & \\
\hline a. Mean \pm standard error of the mean (SEM) & & \\
\hline
\end{tabular}

Figure 3 shows the prevalence of LN metastasis and the tumor budding value. The prevalence of LN metastasis in tumors with five tumor buds was $28.6 \%$. Tumors with five or more buds had higher rates of LN metastasis than did tumors with fewer than five tumor buds. The highest summed sensitivity and specificity values for $L N$ metastasis were 2 and 5, respectively (1.24 and 1.23, respectively). The cut-off number was determined using the AIC from the tumor budding logistic regression models, adjusted for histological type and lymphatic or venous invasion. The AIC value was lowest (246.8) for tumors with five buds (Fig. 4). Thus, the optimal tumor budding cut-off number was five.

In a multivariate analysis using a cut-off of five, unfavorable differentiation (odds ratio [OR], 8.16; $95 \%$ confidence interval [Cl], $1.80-36.89 ; p=0.006)$, positive lymphatic or venous invasion $(\mathrm{OR}, 5.91 ; 95 \% \mathrm{Cl}$, 2.91-11.97; $\mathrm{p}<0.001$ ), and tumor budding ( $\geq$ 5/high-power field [HPF]; OR, 3.01; 95\% Cl, $1.21-7.69 ; p=$ 0.002) were significant predictive parameters for $L N$ metastasis (Table 2). In the multivariate model, the coefficients for histological type, lymphatic or venous invasion, and tumor budding were $2.10,1.78$, and 1.10 , respectively. By adding rounded coefficients, a composite score was developed $(2 \times$ histological type [favorable differentiation, 0 ; unfavorable differentiation, 1] $+2 \times$ lymphatic or venous invasion [negative, 0 ; positive, 1$]+1 \times$ tumor budding $[<5 / \mathrm{HPF}, 0 ; \geq 5 / \mathrm{HPF}, 1])$. Higher composite scores were associated with higher rates of $\mathrm{LN}$ metastasis $(5.6 \%, 15.5 \%, 31.0 \%$, and $52.4 \%$ for total composite scores of $0,1,2$, and $\geq 3$, respectively; Fig. 5).

Table 2

Multivariate analysis of Lymph node (LN) metastasis.

\begin{tabular}{|llll|}
\hline Parameter & OR & $95 \% \mathrm{Cl}$ & $\boldsymbol{P}$ \\
\hline $\begin{array}{l}\text { Histological type } \\
\text { (unfavorable vs. favorable) }\end{array}$ & 8.16 & $1.80-36.89$ & 0.006 \\
\hline $\begin{array}{l}\text { Lymphatic or venous invasion } \\
\text { (positive vs. negative) }\end{array}$ & 5.91 & $2.91-11.97$ & $<0.001$ \\
\hline $\begin{array}{l}\text { Tumor budding } \\
(\geq 5 \text { vs. }<5 / \mathrm{HPF})\end{array}$ & 3.01 & $1.21-7.69$ & 0.002 \\
\hline
\end{tabular}




\section{Discussion}

For the estimation of LN metastasis in submucosal CRC, the optimal tumor budding cut-off number was five. Imai reported that tumor budding or sprouting reflects faster tumor growth (25). In 1989, tumor budding was defined by Morodomi as a cluster of five or more cells that sprouted from tumor cells, regardless of tubular structure status (26). In addition, to determine the degree of budding, a pathological tissue slide was divided into four areas with dimensions of $500 \cdot 2,500 \mu \mathrm{m}$, and the mean number of buds per area was calculated (25). The Japanese classification defines a tumor budding as an isolated single cell or cluster of cells consisting of fewer than five cells at the invasive margin of a tumor (27). In the present study, buds were enumerated using a 10. ocular lens at 20. magnification, in accordance with the Japanese classification. The tumor budding grade according to the number of buds in a $0.785-\mathrm{mm}^{2}$ field was defined as follows: grade 1, 0-4; grade 2, 5-9; and grade 3, $\geq 10$ (27). A multicenter study by the Budding Investigation Project Committee of the Japanese Society for Cancer of the Colon and Rectum, in which grade 1 was defined as low grade and grade 2/3 was defined as high grade, showed that a high grade was associated with LN metastasis (27). When LN metastasis status was verified according to the number of tumor budding, the OR for five or more buds was 8.0 (26). In the present study, the rate of LN metastasis increased as the number of tumor buds increased. The AIC value was lowest with five tumor buds; thus, five was the optimal cut-off value, consistent with the definition of low grade in the Japanese classification. The presence of five or more buds was independently associated with LN metastasis.

The histopathological predictors of LN metastasis in submucosal CRC were the depth of invasion (submucosal invasion $\geq 1,000 \mu \mathrm{m}$ ), unfavorable differentiation (poorly differentiated, mucinous carcinoma, or signet-ring cell carcinoma), and lymphatic or venous invasion. We confirmed that unfavorable differentiation and lymphatic or venous invasion were independent predictors in a multivariate analysis. Ryu et al. reported that lymphatic invasion and histopathological differentiation were significant risk factors in 179 patients with early CRC (28). In a meta-analysis, lymphatic invasion was the most important predictor of LN metastasis; histological grade was also a key predictor (29). The European Society for Medical Oncology, Japanese Society for Cancer of the Colon and Rectum, National Comprehensive Cancer Network, and Korean clinical practice guidelines recommend additional radical operations after endoscopic resection of submucosal cancer in patients with an unfavorable histological grade, deep submucosal invasion, lymphatic or venous invasion, or tumor budding $(21,22,30,31)$. A limitation of the present study was that it did not confirm the depth of invasion. However, a populationbased cohort study demonstrated that age $<60$ years, mucinous carcinoma, lymphovascular invasion, and perineural invasion were independent predictive factors, whereas deep submucosal invasion was not significant in the multivariate analysis $(p=0.075)$, for patients with submucosal CRC undergoing a radical operation (32).

The prevalence of $L N$ metastasis is $10-15 \%$ in patients who undergo additional operations after endoscopic resection (32-34). In our study, the prevalence of LN metastasis was $13.2 \%$. Most patients without LN metastasis are at risk of surgical complications. To avoid unnecessary radical surgery and 
failure to identify LN metastasis, a more precise predictive model for LN metastasis is needed. Several prediction models for LN metastasis in submucosal CRC have been developed (35-37). The least absolute shrinkage and selection operator prediction model includes histopathological factors (35); nomograms that included independent clinicopathological factors have also been used to estimate $L N$ metastasis $(36,37)$. These predictive models have good discriminatory power. We developed a simple prediction scoring system for $\mathrm{LN}$ metastasis that can be applied in daily clinical practice. The relative risk of $\mathrm{LN}$ metastasis increased as the total composite score increased. Patients with a total composite score $\geq 2$ had a LN metastasis rate $>30 \%$. Additional surgery is recommended for these patients.

To our knowledge, this is one of few studies to investigate the optimal tumor budding cut-off number. However, our study was conducted in a single institution; some variables, including depth of invasion, were not fully available because of the retrospective design. A prospective, multi-center study is needed to obtain more accurate and detailed results.

\section{Conclusions}

For the estimation of LN metastasis in submucosal CRC, the optimal tumor budding cut-off number was five. Our CSS can be utilized to estimate LN metastasis.

\section{Abbreviations}

AIC: Akaike information criteria

ASA: American Society of Anesthesiologists

BMl: Body mass index

CEA: carcinoembryonic antigen

Cl: confidence interval

CRC: Colorectal cancer

CSS: composite scoring system

HPF: high-power field

LN: lymph node

OR: odds ratio

\section{Declarations}

\section{Ethics approval and consent to participate}


This study was reviewed and approved by the Institutional Review Board of the Seoul National University Hospital Biomedical Research Institute (approval number: H-2107-045-1232). Informed consent was obtained from all patients. All procedures were carried out in accordance with the relevant guidelines and regulations.

\section{Consent for publication}

Not applicable.

\section{Availability of data and materials}

The datasets generated and/or analyzed during the current study are not publicly available due to ethical restrictions but are available from the corresponding author on reasonable request.

\section{Competing interest}

The authors declare that there is no conflict of interest.

\section{Funding}

This work was supported by the Korean government (MSIT) Grant No. 2021R1F1A1063000 from the National Research Foundation of Korea (NRF).

\section{Authors' contributions}

JKK and YYR wrote the manuscript. SJK, HJL, JPI, JMB and JHK performed some of the lab work and data collection. MJK, SBR, SYJ and KJP supported the overall data analysis and provided constructive discussion. JKK, YYR, GHK and JWP conceived and designed the study. All authors read and approved the final manuscript.

\section{Acknowledgements}

Not applicable.

\section{Authors' information}

Jeong-ki Kim and Ye-Young Rhee contributed equally to this work.

Affiliations

Department of Surgery, Chung-Ang University Hospital, Seoul 06973, Republic of Korea

Chung-Ang University College of Medicine, Seoul 06973, Republic of Korea

Jeong-ki Kim 
Pathology Center, Seegene Medical Foundation, Seoul 05542, Republic of Korea

Ye-Young Rhee

Department of Pathology, Seoul National University College of Medicine, Seoul 03080, Republic of Korea

Jeong Mo Bae, Jung Ho Kim, and Gyeong Hoon Kang

Department of Internal Medicine, Seoul National University College of Medicine, Seoul 03080, Republic of Korea

Seong-Joon Koh, Hyun Jung Lee, and Jong Pil Im

Department of Surgery, Seoul National University College of Medicine, Seoul 03080, Republic of Korea

Min Jung Kim, Ji Won Park, Seung-Bum Ryoo, Seung-Yong Jeong, and Kyu Joo Park

Cancer Research Institute, Seoul National University, Seoul 03080, Republic of Korea

Min Jung Kim, Ji Won Park and Seung-Yong Jeong

Corresponding authors

Correspondence to Ji Won Park and Gyeong Hoon Kang

\section{References}

1. Greenlee RT, Hill-Harmon MB, Murray T, Thun M. Cancer statistics, 2001. CA Cancer J Clin. 2001;51(1):15-36.

2. Gill S, Loprinzi CL, Sargent DJ, Thomé SD, Alberts SR, Haller DG, et al. Pooled analysis of fluorouracilbased adjuvant therapy for stage II and III colon cancer: who benefits and by how much? J Clin Oncol. 2004;22(10):1797-806.

3. Beaton C, Twine CP, Williams GL, Radcliffe AG. Systematic review and meta-analysis of histopathological factors influencing the risk of lymph node metastasis in early colorectal cancer. Colorectal Dis. 2013;15(7):788-97.

4. Ueno H, Mochizuki H, Hashiguchi Y, Shimazaki H, Aida S, Hase K, et al. Risk factors for an adverse outcome in early invasive colorectal carcinoma. Gastroenterology. 2004;127(2):385-94.

5. Tominaga K, Nakanishi Y, Nimura S, Yoshimura K, Sakai Y, Shimoda T. Predictive histopathologic factors for lymph node metastasis in patients with nonpedunculated submucosal invasive colorectal carcinoma. Diseases of the colon and rectum. 2005;48(1):92-100.

6. Sohn DK, Chang HJ, Park JW, Choi DH, Han KS, Hong CW, et al. Histopathological risk factors for lymph node metastasis in submucosal invasive colorectal carcinoma of pedunculated or semipedunculated type. J Clin Pathol. 2007;60(8):912-5. 
7. Glasgow SC, Bleier JI, Burgart LJ, Finne CO, Lowry AC. Meta-analysis of histopathological features of primary colorectal cancers that predict lymph node metastases. J Gastrointest Surg. 2012;16(5):1019-28.

8. Suh JH, Han KS, Kim BC, Hong CW, Sohn DK, Chang HJ, et al. Predictors for lymph node metastasis in T1 colorectal cancer. Endoscopy. 2012;44(6):590-5.

9. Macias-Garcia F, Celeiro-Muñoz C, Lesquereux-Martinez L, Gude-Sampedro F, Uribarri-Gonzalez L, Abdulkader I, et al. A clinical model for predicting lymph node metastasis in submucosal invasive (T1) colorectal cancer. International journal of colorectal disease. 2015;30(6):761-8.

10. Haggitt RC, Glotzbach RE, Soffer EE, Wruble LD. Prognostic factors in colorectal carcinomas arising in adenomas: implications for lesions removed by endoscopic polypectomy. Gastroenterology. 1985;89(2):328-36.

11. Okabe S, Shia J, Nash G, Wong WD, Guillem JG, Weiser MR, et al. Lymph node metastasis in T1 adenocarcinoma of the colon and rectum. J Gastrointest Surg. 2004;8(8):1032-9; discussion 9-40.

12. Shimomura $T$, Ishiguro $S$, Konishi $H$, Wakabayashi N, Mitsufuji $S$, Kasugai $T$, et al. New indication for endoscopic treatment of colorectal carcinoma with submucosal invasion. J Gastroenterol Hepatol. 2004;19(1):48-55.

13. Egashira Y, Yoshida T, Hirata I, Hamamoto N, Akutagawa H, Takeshita A, et al. Analysis of pathological risk factors for lymph node metastasis of submucosal invasive colon cancer. Mod Pathol. 2004;17(5):503-11.

14. Ogino S, Nosho K, Irahara N, Meyerhardt JA, Baba Y, Shima K, et al. Lymphocytic reaction to colorectal cancer is associated with longer survival, independent of lymph node count, microsatellite instability, and CpG island methylator phenotype. Clin Cancer Res. 2009;15(20):6412-20.

15. Lugli A, Kirsch R, Ajioka Y, Bosman F, Cathomas G, Dawson H, et al. Recommendations for reporting tumor budding in colorectal cancer based on the International Tumor Budding Consensus Conference (ITBCC) 2016. Mod Pathol. 2017;30(9):1299-311.

16. Lugli A, Karamitopoulou E, Zlobec I. Tumour budding: a promising parameter in colorectal cancer. $\mathrm{Br}$ J Cancer. 2012;106(11):1713-7.

17. Mitrovic B, Schaeffer DF, Riddell RH, Kirsch R. Tumor budding in colorectal carcinoma: time to take notice. Mod Pathol. 2012;25(10):1315-25.

18. van Wyk HC, Park J, Roxburgh C, Horgan P, Foulis A, McMillan DC. The role of tumour budding in predicting survival in patients with primary operable colorectal cancer: a systematic review. Cancer Treat Rev. 2015;41(2):151-9.

19. De Smedt L, Palmans S, Sagaert X. Tumour budding in colorectal cancer: what do we know and what can we do? Virchows Arch. 2016;468(4):397-408.

20. Rogers AC, Winter DC, Heeney A, Gibbons D, Lugli A, Puppa G, et al. Systematic review and metaanalysis of the impact of tumour budding in colorectal cancer. Br J Cancer. 2016;115(7):831-40.

21. Argilés G, Tabernero J, Labianca R, Hochhauser D, Salazar R, Iveson T, et al. Localised colon cancer: ESMO Clinical Practice Guidelines for diagnosis, treatment and follow-up. Ann Oncol. 
2020;31(10):1291-305.

22. Hashiguchi Y, Muro K, Saito Y, Ito Y, Ajioka Y, Hamaguchi T, et al. Japanese Society for Cancer of the Colon and Rectum (JSCCR) guidelines 2019 for the treatment of colorectal cancer. Int J Clin Oncol. 2020;25(1):1-42.

23. Nishida T, Egashira Y, Akutagawa H, Fujii M, Uchiyama K, Shibayama Y, et al. Predictors of lymph node metastasis in T1 colorectal carcinoma: an immunophenotypic analysis of 265 patients. Diseases of the colon and rectum. 2014;57(8):905-15.

24. Kim BH, Kim JM, Kang GH, Chang HJ, Kang DW, Kim JH, et al. Standardized Pathology Report for Colorectal Cancer, 2nd Edition. Journal of pathology and translational medicine. 2020;54(1):1-19.

25. Imai T. Growth patterns in human carcinoma. Their classification and relation to prognosis. Obstet Gynecol. 1960;16:296-308.

26. Morodomi T, Isomoto H, Shirouzu K, Kakegawa K, Irie K, Morimatsu M. An index for estimating the probability of lymph node metastasis in rectal cancers. Lymph node metastasis and the histopathology of actively invasive regions of cancer. Cancer. 1989;63(3):539-43.

27. Watanabe T, Itabashi M, Shimada Y, Tanaka S, Ito Y, Ajioka Y, et al. Japanese Society for Cancer of the Colon and Rectum (JSCCR) guidelines 2010 for the treatment of colorectal cancer. Int J Clin Oncol. 2012;17(1):1-29.

28. Ryu HS, Kim WH, Ahn S, Kim DW, Kang SB, Park HJ, et al. Combined morphologic and molecular classification for predicting lymph node metastasis in early-stage colorectal adenocarcinoma. Ann Surg Oncol. 2014;21(6):1809-16.

29. Bosch SL, Teerenstra S, de Wilt JHW, Cunningham C, Nagtegaal ID. Predicting lymph node metastasis in PT1 colorectal cancer: a systematic review of risk factors providing rationale for therapy decisions. Endoscopy. 2013;45(10):827-41.

30. Benson AB, Venook AP, Al-Hawary MM, Arain MA, Chen YJ, Ciombor KK, et al. Colon Cancer, Version 2.2021, NCCN Clinical Practice Guidelines in Oncology. J Natl Compr Canc Netw. 2021;19(3):329-59.

31. Park CH, Yang DH, Kim JW, Kim JH, Kim JH, Min YW, et al. Clinical Practice Guideline for Endoscopic Resection of Early Gastrointestinal Cancer. Clin Endosc. 2020;53(2):142-66.

32. Rönnow CF, Arthursson V, Toth E, Krarup PM, Syk I, Thorlacius H. Lymphovascular Infiltration, Not Depth of Invasion, is the Critical Risk Factor of Metastases in Early Colorectal Cancer: Retrospective Population-based Cohort Study on Prospectively Collected Data, Including Validation. Annals of surgery. 2022;275(1):e148-e154

33. Belderbos TD, van Erning FN, de Hingh IH, van Oijen MG, Lemmens VE, Siersema PD. Long-term Recurrence-free Survival After Standard Endoscopic Resection Versus Surgical Resection of Submucosal Invasive Colorectal Cancer: A Population-based Study. Clin Gastroenterol Hepatol. 2017;15(3):403-11 e1.

34. Makimoto S, Takami T, Hatano K, Kataoka N, Yamaguchi T, Tomita M, et al. Additional surgery after endoscopic submucosal dissection for colorectal cancer: a review of 53 cases. International journal of colorectal disease. 2019;34(10):1723-9.

Page 13/18 
35. Backes Y, Elias SG, Groen JN, Schwartz MP, Wolfhagen FHJ, Geesing JMJ, et al. Histologic Factors Associated With Need for Surgery in Patients With Pedunculated T1 Colorectal Carcinomas. Gastroenterology. 2018;154(6):1647-59.

36. Oh JR, Park B, Lee S, Han KS, Youk EG, Lee DH, et al. Nomogram Development and External Validation for Predicting the Risk of Lymph Node Metastasis in T1 Colorectal Cancer. Cancer Res Treat. 2019;51(4):1275-84.

37. Guo K, Feng Y, Yuan L, Wasan HS, Sun L, Shen M, et al. Risk factors and predictors of lymph nodes metastasis and distant metastasis in newly diagnosed T1 colorectal cancer. Cancer Med. 2020;9(14):5095-113.

\section{Figures}

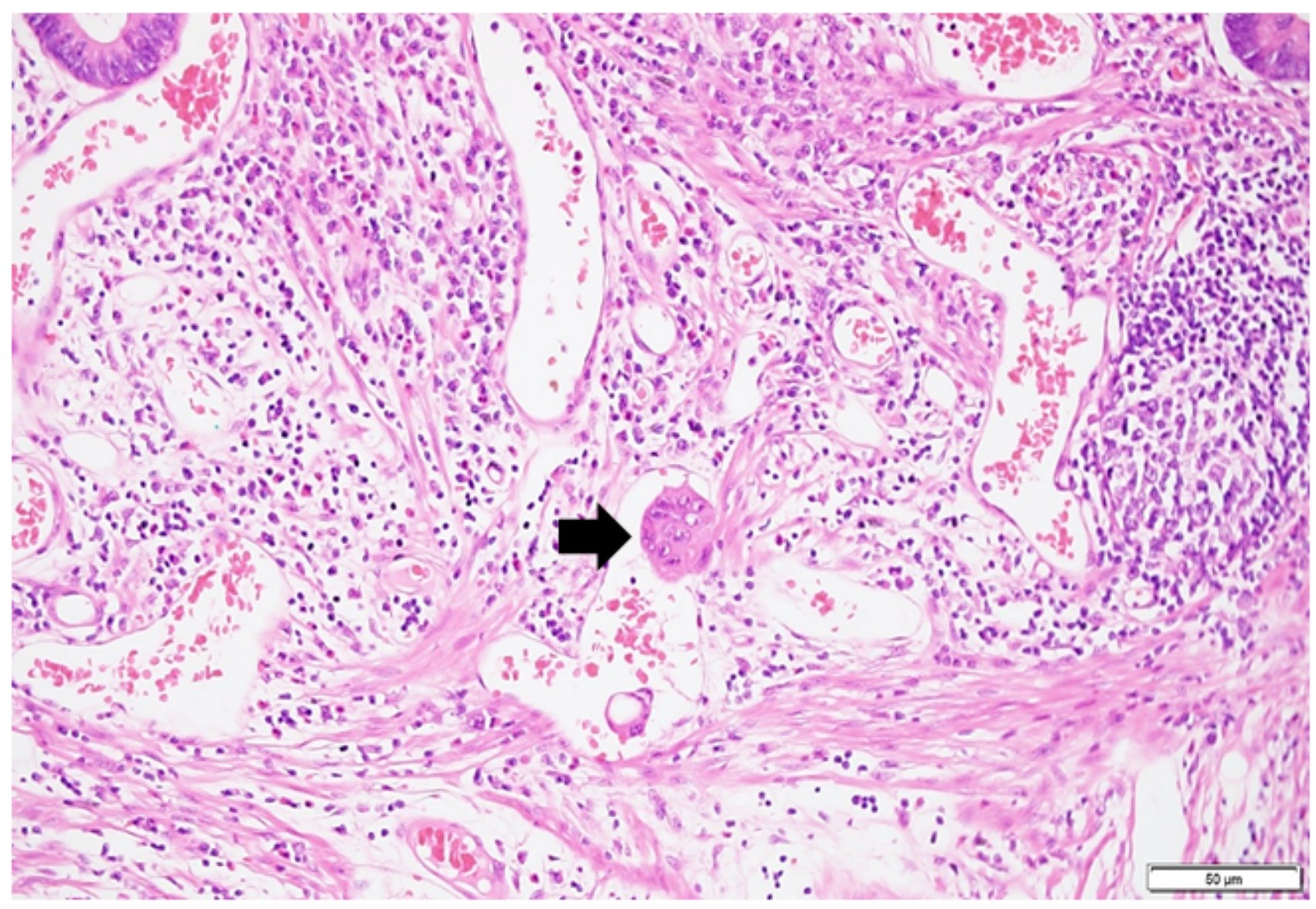

\section{Figure 1}

Representative histopathological image of lymphatic or venous invasion (hematoxylin and eosin staining, $\times 200)$. 


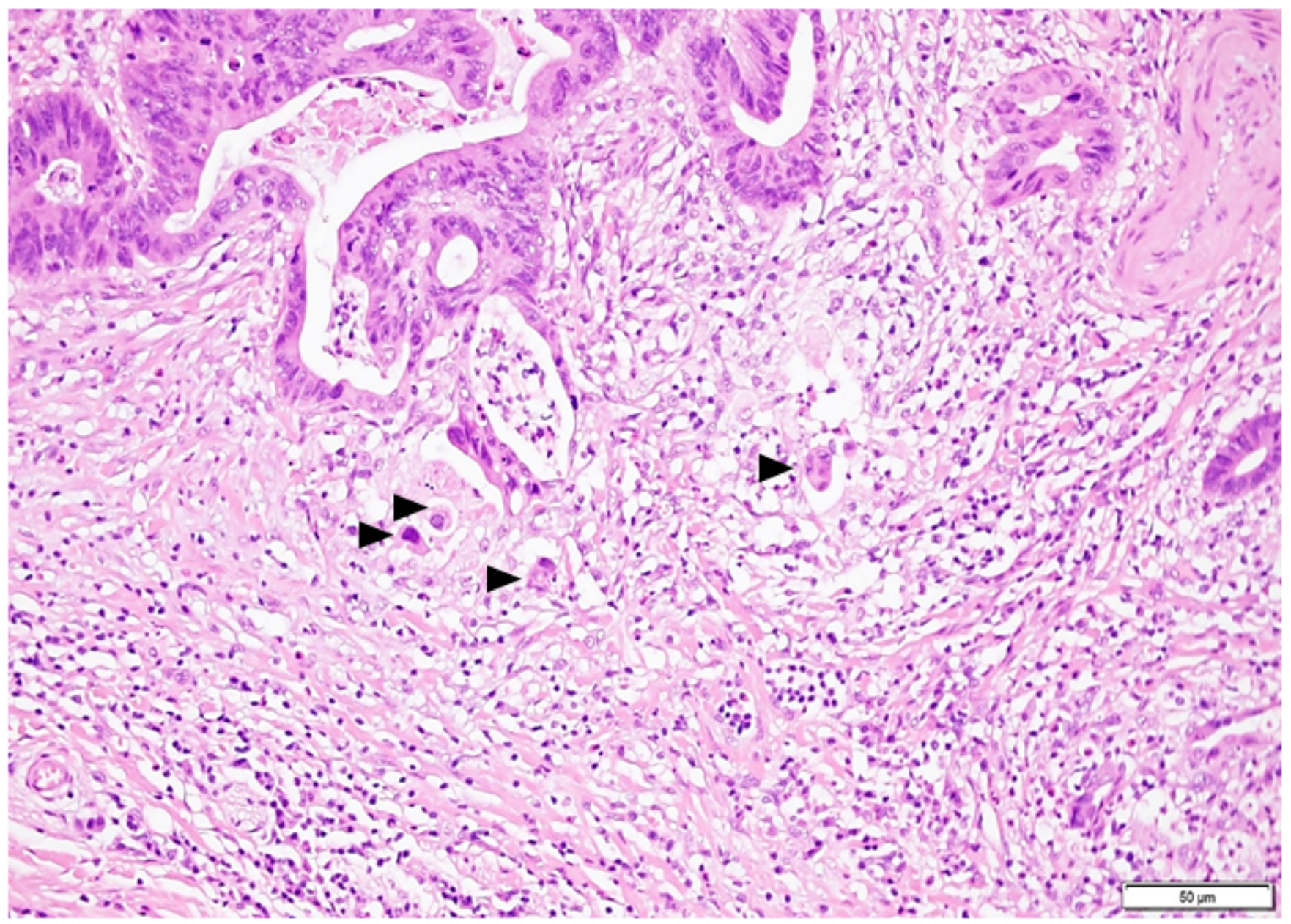

Figure 2

Representative histopathological image of tumor budding, isolated single cells, or clusters of up to four cells (hematoxylin and eosin staining, $\times 200$ ). 


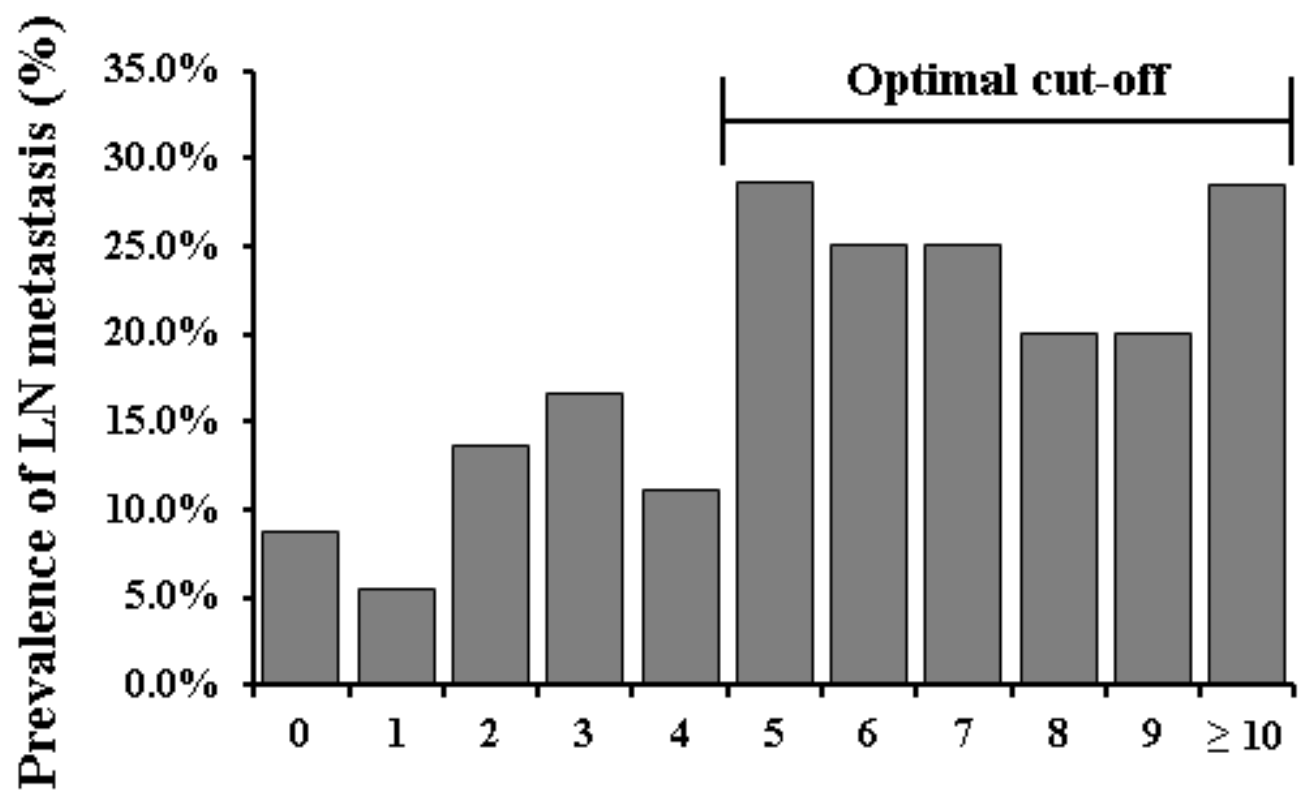

Number of tumor budding (n)

Figure 3

The prevalence of lymph node ( $L N)$ metastasis is associated with the number of tumor budding. 


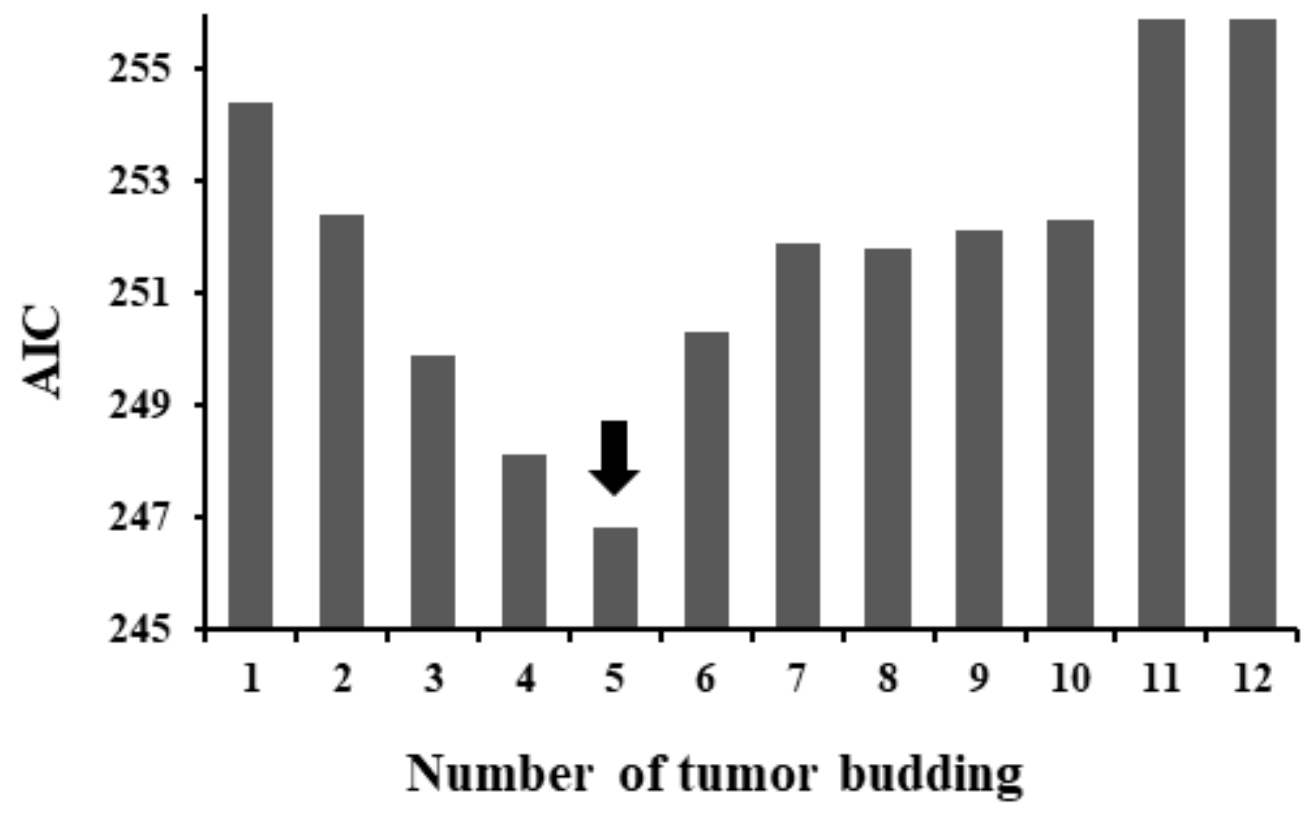

Figure 4

Akaike information criterion (AIC) in logistic regression models adjusted for histological type and lymphatic or venous invasion. 


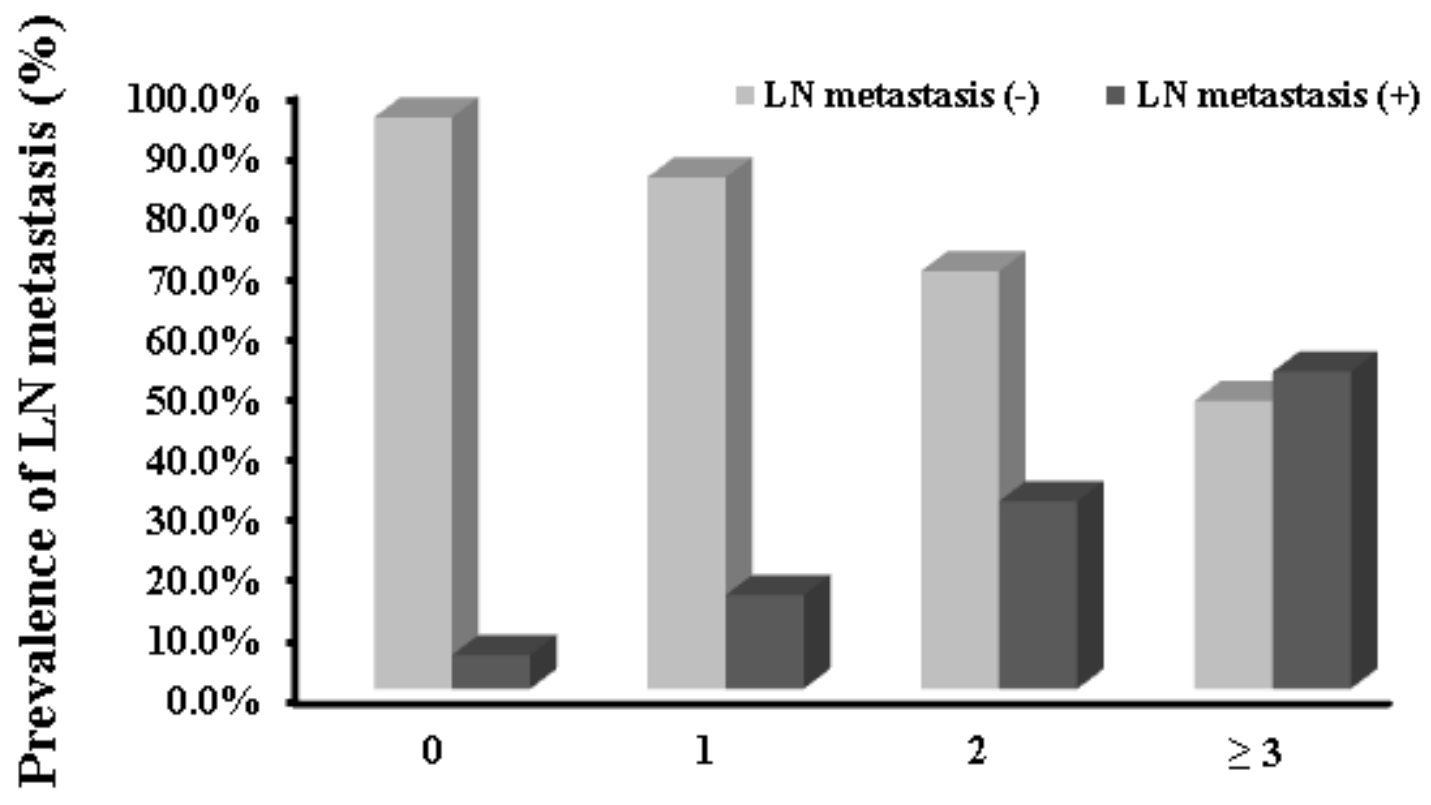

Total composite score

Figure 5

Prevalence of lymph node $(\mathrm{LN})$ metastasis according to the total composite score. Total composite score: $2 \times$ histological type [favorable differentiation, 0 ; unfavorable differentiation, 1] $+2 \times$ lymphatic or venous invasion [negative, $0 ;$ positive, 1$]+1 \times$ tumor budding $[<5 / \mathrm{HPF}, 0 ; \geq 5 / \mathrm{HPF}, 1]$ 